\title{
A General Theory of Location Based on the Notion of Entire Location
}

\author{
Fabrice Correia ${ }^{1}$
}

Received: 12 May 2021 / Accepted: 7 October 2021 / Published online: 7 January 2022

(C) The Author(s) 2021

\begin{abstract}
It would be a good thing to have at our disposal a general theory of location that is neutral with respect to (i.e. that does not rule out or entail) (i) the view that some objects have more than one exact location, (ii) the view that some objects are located without having an exact location, and (iii) the view that some objects are "spanners"- - where a spanner is an object exactly located at a region that has proper parts but which has no proper part exactly located at a proper part of the region. As far as I know, no theory of location that can be found in the literature has this feature. I put forward a new theory that does - or so I argue. The theory takes as its sole locational primitive the notion of being entirely located at.
\end{abstract}

Keywords Location $\cdot$ Multilocation $\cdot$ Inexact location $\cdot$ Spanners

\section{Introduction}

The notion of location is "formal" or "topic-neutral", at least to a certain extent. ${ }^{1}$ When we ascribe a location to something, we have in mind a space (or perhaps better: system) of regions - a structured collection of possible locations - and the spaces of regions are legion, in numbers but also in kinds. When we ascribe a location to something, we may have in mind a space whose regions are the time instants and fusions thereof; or a space whose regions are the parts of physical space; or a space whose regions are the parts of spacetime. But the list is much longer. When playing chess, we focus on a space of regions that comprises only 64 of the myriad parts of the (surface of) the chessboard; when we inquire about where people live, we may be interested in a space consisting solely of places of residence; and the regions of what are sometimes called "quality spaces' are yet another kind of beast since they are abstract. The "occupier side" of the

${ }^{1}$ This is not often stressed. See [1] for an explicit statement.

Fabrice Correia

fabrice.correia@unige.ch

1 Department of Philosophy, University of Geneva, Rue De-Candolle 5, 1211 Geneva 4, Switzerland 
notion also displays categorial variety, in some cases even when the space of regions is fixed: for instance, the occupiers of physical space or spacetime may include material objects, but also events or tropes.

Most of the philosophical work on location has been done by people who focused on location in time, physical space or spacetime. My aim in this paper is to formulate a theory of location that is general, in the sense of being neutral regarding the nature of the spaces of regions and the nature of what occupies them - in much the same way as mereology is sometimes said to be neutral with respect to the nature of its relata. Whether full generality is achievable or not I do not know. Be that as it may, the aimmore carefully put - is to formulate a theory that is reasonably general.

Current theorising about location distinguishes between several different relations of location. Two of them have come to occupy centre stage, and they are also central to the present inquiry: weak location and exact location. ${ }^{2}$ Informally characterising them without prejudging substantial issues is no easy task, but here is a relatively neutral way of doing it in the case of weak location (here and below, I use ' $x$ ', ' $y$ ', etc. for occupiers of regions - which I will often call simply 'objects' - and ' $R$ ', ' $S$ ', etc. for regions; principles stated with free variables will throughout have to be understood as universally closed):

- $\mathrm{x}$ is weakly located at $\mathrm{R}$ iff $\mathrm{R}$ is not completely free of $\mathrm{x}$ ([2]: 203).

The case of exact location is trickier. The following characterisation offered by Cody Gilmore has become influential:

- $\quad \mathrm{x}$ is exactly located at $\mathrm{R}$ iff $\mathrm{x}$ has (or has-at-R) exactly the same shape and size as $\mathrm{R}$ and stands (or stands-at-R) in all the same spatial or spatiotemporal relations to other entities as does R ([19]: §2.1; see also [3]: 1228 for a formulation without the bracketed qualifications).

The bracketed qualifications in Gilmore's characterisation are motivated by the desire to leave open the possibility that an object be exactly located at two or more regions with different shapes or with different spatial or spatiotemporal relations to other entities (see [4]: 227-228). Figure 1 is intended to represent a single grey object, $\Omega$, that is weakly located at all the labelled regions and exactly located at both regions R4 and R5 and at no other labelled region. Importantly, the figure is neutral on whether $\Omega$ is also exactly located at the fusion R4 + R5 of R4 and R5. I take it that it can be maintained that it is not. ${ }^{3}$

Popular as Gilmore's gloss on exact location may be, it is important to bear in mind that it is not neutral on the nature of the space of regions at stake. The gloss is appropriate, I take it, when the regions are for instance those of a 3D Euclidean space, or of a 2D Euclidean surface, or of a 4D Minkowski spacetime: in these cases, talk of shapes and their sizes makes perfect sense. But in some cases, talk of shapes or size

\footnotetext{
${ }^{2}$ The labels are standard and come from [2]. I will also borrow the labels 'entire location' and 'pervasive location' from that paper. What is there meant by 'exact location' and 'entire location', though, is not exactly what I mean-see $\$ 3$.

${ }^{3}$ For an argument that $\Omega$ is not also exactly located at the fusion, see [5]: 29-30. I will discuss a principle, Restricted Multilocation, that has the same consequence ( $\$ 5)$.
} 

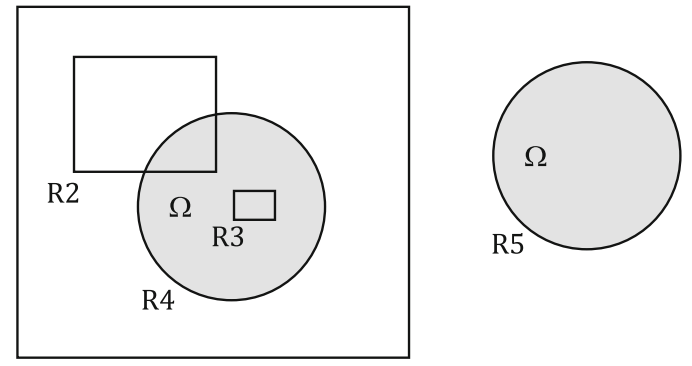

R1

Fig. 1 Weak and exact location

simply makes no sense because the space of regions at stake does not have a metric (think for instance of the space of regions consisting of the nodes of a mathematical labelled tree, whose labels construed as the occupiers of the nodes). ${ }^{4}$

These two relations allow one to formulate three principles that fuelled many discussions in the recent literature. One rules out the situations that motivate the careful formulation of the informal characterisation of exact location given above: ${ }^{5}$

\section{Functionality}

No object is exactly located at more than one region.

Another one connects weak location and exact location:

\section{Exactness}

Every object that is weakly located is exactly located.

The third principle, like the first one, is formulated solely in terms of exact location. Let a spanner be an object $\mathrm{x}$ that is exactly located at some region $\mathrm{R}$ such that (i) $\mathrm{R}$ has proper parts, (ii) there is no proper part $\mathrm{S}$ of $\mathrm{R}$ and part $\mathrm{y}$ of $\mathrm{x}$ such that $\mathrm{y}$ is exactly located at $\mathrm{S} .{ }^{6}$ The principle is the following:

\section{No Spanners}

There are no spanners.

Let a domain be a pair consisting of a space of regions and a set of occupiers. Say that a theory of location is neutral with respect to a principle among the three just formulated iff (i) it explicitly features (as primitive or as defined) the relevant locational notion(s), and (ii) it is both compatible with the truth of the principle relative to some domain and compatible with the falsity of the principle relative to some domain. And say that a theory of location is NEUTRAL iff it is neutral with respect to the three principles. As I argue in the next section, if one is, like me, interested in formulating general theories of

\footnotetext{
${ }^{4}$ This point will be crucial in my discussion of a situation put forward by Shieva Kleinschmidt [6] in $\S 8$.

5 The names of the first two principles are also from [2], but Parsons' principles are not exactly those I introduce here. His principles are formulated in terms of what I will call 'P-exact location' rather than in terms of exact location (see $\S 3$ ).

6 The label 'spanner' comes from [7]: 101.
} 
location, there are good reasons for willing to devise a general theory of location that is NEUTRAL. As far as I know, no theory among those that can be found in the literature has that feature. The theory that I offer below is intended to have it.

My plan is as follows. In $\S 2$, I motivate the view that formulating a NEUTRAL theory of location is desirable for anyone interested in formulating general theories of location. In $\S 3$, I argue that extant theories of location fail to be NEUTRAL. In $\S 4$, I introduce my own theory-a theory based on the notion of entire location - and argue that it is NEUTRAL. In $\S 5$, I give an account of multilocation that does not imply that multilocated objects have exact locations. In $\S 6$, I identify an important principle, Exactitude - akin to, but more general than, Exactness - examine its consequences and establish a sufficient condition for it to obtain. In $\S 7$, I apply the account of multilocation developed in $\S 5$ to the characterisation of the endurantism vs perdurantism debate that does not presuppose that enduring objects and perduring objects are exactly located. Finally, in $\S 8$, I reply to some objections against my theory.

\section{Why NEUTRALITY?}

The reason why I hold that it is desirable to formulate a general theory of location that is NEUTRAL if we are interested in formulating general theories of location in the first place is the following. If one focuses on certain specific domains, for instance on spacetime and the events that occupy it, then one may easily be convinced that Functionality, Exactness and No Spanners must hold. But when one starts to think about various kinds of domains, it seems to me, one will see that given any principle $\mathrm{P}$ among Functionality, Exactness and No Spanners, it is conceptually possible that $\mathrm{P}$ be true relative to some domain and it is conceptually possible that $\mathrm{P}$ be false relative to some (perhaps different) domain. Given that there are all these possibilities and given that one is interested in formulating general theories of location, one clearly has a good motivation for trying to formulate a NEUTRAL theory.

The only part of the previous argument that needs to be defended, I assume, is the claim that given any principle among the three listed in the previous section, it is both conceptually possible that the principle be true relative to some domain and conceptually possible that the principle be false relative to some domain. I take it that I do not need to argue for the positive part of the claim, namely for the claim that for each principle, it is conceptually possible that the principle be true relative to some domain. For the negative part of the claim, let me go through each principle in turn.

I find the following two arguments to the effect that Functionality is not conceptually necessary particularly convincing:

The ARGUMENT FROM ENDURING OBJECTS. On a standard view, objects like people, chairs and rocks endure, where this is taken to mean that they persist through time by being exactly located at various, non-overlapping three-dimensional regions of spacetime - so-called achronal regions (see [4]: 204-206). Since enduring objects are conceptually possible, the argument goes, Functionality is not conceptually necessary. 
THE ARGUMENT FROM TIME TRAVEL ([3]: 1242). This argument also invokes enduring objects, but in a different way. If Sven, an enduring person, travels to the past and meets himself at some time in 1970, there is a time at which he is exactly located at distinct spatial regions. Since such a scenario is conceptually possible, Functionality is not conceptually necessary.

Here is one argument to the effect that Exactness is not conceptually necessary that I also find convincing: ${ }^{7}$

THE ARgUMENT FROM GUNKY SPACE ([2]: 207). It is conceptually possible that physical space is gunky (that is, such that any of its regions has proper subregions), that none of its regions is point-shaped and that there exists a pointshaped material object. If physical space has the features just mentioned, then no point-shaped object can exactly occupy a region of that space. A material object must weakly occupy some such region. Therefore, it is conceptually possible that Exactness fails. Focus on physical space rather than spacetime is here only for the sake of definiteness - the argument can be formulated, mutatis mutandis, by referring to spacetime rather than physical space.

These arguments focus on a space consisting of the regions of physical space or spacetime, and I would also be happy to claim that violations of No Spanners relative to these spaces of regions are conceptually possible. But since I know that many would disagree, let me invoke another kind of space of regions:

The ARgument From homes. Consider the space of regions consisting of the homes of people and their pets in a given town. A home of a person or a pet is an exact location of that person or pet relative to this space of regions. Consider a building in the town that is divided into various flats in which people live. We may suppose, as is standard, that each person living in the building has one and only one home, which is a flat in the building. Now we may also suppose that some cat, which belongs to someone who lives in the building, has the entire building as a home, and nothing else. The cat is a spanner: it is exactly located at the building without having parts exactly located at the various flats in the building. Such a scenario is conceptually possible (indeed, there are real life scenarios of that sort) and therefore No Spanners is not conceptually necessary.

So-called extended simples - objects that have no proper parts, but which are exactly located at regions that do have proper parts - are spanners of a particular sort. Given that spanners are conceptually possible, I take it, so are extended simples.

This concludes my argument for the claim that it is desirable to formulate a NEUTRAL general theory of location if we are interested in formulating general theories of location at all. One important caveat before moving on, though. It is not built into the notion of NEUTRALITY that a NEUTRAL theory of location must be "absolutely neutral", i.e. compatible with any conceptual possibility regarding locational situations. NEUTRALITY as I

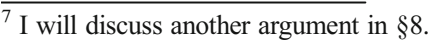


defined it in the previous section is a restricted form of neutrality- I am using small caps for the label that expresses the notion precisely to signal that this notion is restricted in a certain way. The theory I put forward in $\S 4$ is intended to be NEUTRAL, but I certainly do not want to make the stronger claim that it is absolutely neutral (even though, of course, I would be happy if it were).

\section{Extant Theories and NEUTRALITY}

As I previously stressed, no theory of location that I know of is NEUTRAL. Let me here substantiate this claim and establish some general facts along the way.

Josh Parsons' seminal paper on theories of location (2007) offers two important theories of location, one that takes what I will call 'P-exact' location as sole primitive locational notion, and the other one that takes weak location as sole locational primitive instead. Both theories feature four locational notions: P-exact, weak, pervasive and what I will call 'P-entire' location. I previously gave informal characterisations of the second notion. Pervasive and P-entire location can be characterised as follows:

- $\quad \mathrm{x}$ is pervasively located at $\mathrm{R}$ iff $\mathrm{x}$ completely fills $\mathrm{R}$ ([8]: 429).

- $\mathrm{x}$ is $\mathrm{P}$-entirely located at $\mathrm{R}$ iff $\mathrm{R}$ is not completely free of $\mathrm{x}$, and all the regions disjoint from $\mathrm{R}$ are completely free of $\mathrm{x}$ ([2]: 203).

Thus, the grey occupier $\Omega$ in the situation depicted by Fig. 1 is pervasively located at R3, R4 and R5, and at no other labelled region.

I use 'P-exact location' rather than simply 'exact location' as Parsons does, because the relation Parsons takes the latter label to express is not the same as the one I and many others (e.g. Gilmore, from whom I borrowed the informal characterisation of the notion) take it to express. For spaces of regions that are in a certain sense "well behaved" (in my framework: spaces that validate the principle Exactitude, see Proposition 12 (d) in §6), if the regions at which an object $\mathrm{x}$ is exactly located (in my sense) have a fusion $\mathrm{S}$, then $\mathrm{x}$ is P-exactly located at region $\mathrm{R}$ iff $\mathrm{R}=\mathrm{S}$. Hence, given such spaces, if Functionality holds, P-exact location coincides with exact location. But in any situation where Functionality fails, the two notions fail to coincide. In the situation represented by Fig. 1, for instance, $\Omega$ is P-exactly located at $\mathrm{R} 4+\mathrm{R} 5$, and at no other region, while it is exactly located at R4 and at R5.

Likewise, I use 'P-entire location' for what Parsons calls 'entire location' because I will use the latter label for a different notion (the notion my own theory takes as a primitive indeed). My informal characterisation of entire location, as I understand the label, goes as follows:

- $\mathrm{x}$ is entirely located at $\mathrm{R}$ iff $\mathrm{x}$ lies within $\mathrm{R}$.

An object $\mathrm{x}$ is P-entirely located at $\mathrm{R}$ iff $\mathrm{x}$ is entirely located at $\mathrm{R}$ and there is no disjoint region at which $\mathrm{x}$ is weakly located. Thus, P-entire location entails entire location. Failures of Functionality are cases where the converse entailment fails: in the situation depicted by Fig. 1, for instance, $\Omega$ is entirely located at both R4 and R5 while it is Pentirely located at neither (if the regions that do not overlap R4 + R5 are completely 
free of $\Omega, \Omega$ is P-entirely located at a region R iff R4 + R5 is a part of R). Parsons [2] takes it that an object is P-exactly located at a region iff it is both P-entirely and pervasively located at that region. This biconditional corresponds to the definition of Pexact location I give in $\S 4$.

Let me use the following abbreviations for the Parsonsian locational relations mentioned so far:

- 'x P-ex-@ R' for 'x is P-exactly located at R'

- 'x we-@ R' for ' $x$ is weakly located at R'

- 'x pe-@ R' for ' $\mathrm{x}$ is pervasively located at R'

- 'x P-en-@ R' for ' $\mathrm{x}$ is P-entirely located at R'

I will use similar abbreviations for the other two locational relations we have already met:

- 'x ex-@ R' for ' $\mathrm{x}$ is exactly located at R'

- 'x en-@ R' for ' $\mathrm{x}$ is entirely located at R'

I will call these six relations the core relations.

In his theory that takes P-exact location as primitive, Parsons defines weak, P-entire and pervasive location as follows, where ' $O$ ' is for 'overlaps' and ' $\leq$ ' for 'is a (proper or improper) part of':

\section{Parsons\#1}

- $\quad \mathrm{x}$ we-@ $\mathrm{R}$ iff $\mathrm{df}_{\mathrm{f}}$ there is a region $\mathrm{R}^{*}$ such that $\mathrm{x} \mathrm{P}-\mathrm{ex}-@ \mathrm{R}^{*}$ and $\mathrm{R} * \circ \mathrm{R}$.

- $\mathrm{x}$ P-en-@ $\mathrm{R}$ iff $\mathrm{df}_{\mathrm{f}}$ there is a region $\mathrm{R}^{*}$ such that $\mathrm{x} \mathrm{P}-\mathrm{ex}-@ \mathrm{R} *$ and $\mathrm{R} * \leq \mathrm{R}$.

- $\mathrm{x}$ pe-@ $\mathrm{R}$ iff $\mathrm{df}_{\mathrm{f}}$ there is a region $\mathrm{R}^{*}$ such that $\mathrm{x} \mathrm{P}-\mathrm{ex}-@ \mathrm{R} *$ and $\mathrm{R} \leq \mathrm{R}$ *

In the other theory, weak location is used to define P-exact, P-entire and pervasive location as follows:

\section{Parsons\#2}

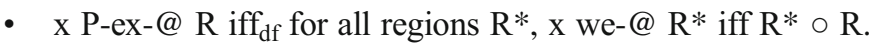

- x P-en-@ $\mathrm{R}$ iff $\mathrm{df}_{\mathrm{x}} \mathrm{we}$-@ $\mathrm{R}$ and for all regions $\mathrm{R}^{*}$, if $\mathrm{x}$ we-@ $\mathrm{R}^{*}$, then $\mathrm{R}^{*} \circ \mathrm{R}$.

- $\mathrm{x}$ pe-@ $\mathrm{R}$ iff $\mathrm{df}$ for all regions $\mathrm{R}^{*}$, if $\mathrm{R}^{*} \circ \mathrm{R}$, then $\mathrm{x}$ we-@ $\mathrm{R}^{*}$.

None of Parsons' two theories features exact location. Since they do not feature exact location, they fail to be NEUTRAL. One may however wonder whether the relation can be defined in these theories. As I will now argue, the answer is negative if the theories are to be NEUTRAL. Each theory has as non-logical primitives only a locational notion and mereological notions. The argument establishes the general fact that P-exact location and weak location are too coarse-grained for exact location to be definable solely in terms of any of them and mereological notions, at any rate if the resulting theory is to be NEUTRAL.

Here is the argument. Consider the two situations depicted in Fig. 2. In Situation 1, a mereologically simple object $\Delta$ is exactly located at two spatial points R6 and R7 but not at their fusion $\mathrm{R} 6+\mathrm{R} 7$, regions $\mathrm{R} 6, \mathrm{R} 7$ and $\mathrm{R} 6+\mathrm{R} 7$ are the only regions that there are, 


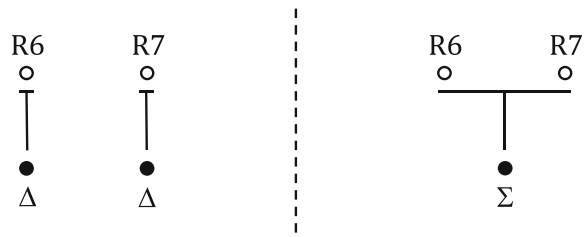

Situation 1

Situation 2

Fig. 2 A multilocated simple and an extended simple

and $\Delta$ is the only object located at a region. Situation 2 is just like Situation 1 except that another mereologically simple object $\Sigma$ takes the place of $\Delta$ and $\Sigma$ is exactly located at R6 $+\mathrm{R} 7$ and only at that region. Thus, $\Sigma$ is an extended simple. I take it that a NEUTRAL theory of location should leave room for such situations. Now except for the fact that they do not have numerically the same occupier, the two situations are mereologically alike, and they do not differ in terms of P-exact location (in both situations, there is a single occupier, and it is P-exactly located at R6 + R7 and at no other regions) or in terms of weak location (in both situations, there is a single occupier, and it is weakly located at all three regions). Since by hypothesis the two situations differ in terms of exact location, it follows that exact location cannot be defined in a NEUTRAL theory solely using mereological notions plus P-exact location or weak location., ${ }^{8,9}$

What about the idea of defining weak location in terms of exact location and taking the latter as a primitive? Consider the idea of adopting the first definition in Parsons\#1 but with exact location replacing P-exact location. The suggested view is that the following definition is correct:

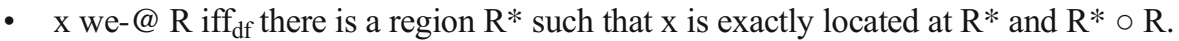

Gilmore [4] endorses this definition (he uses 's-overlapping' instead of 'weak location') and does take exact location to be primitive. Taking exact location to be primitive allows one to leave room for failures of Functionality, and this is precisely what Gilmore wants to do. However, granted the definition, Exactness can be straightforwardly established and therefore the theory is not NEUTRAL.

It might be thought that the culprit is the particular way in which weak location has been defined in terms of exact location. Here is a suggestion of an alternative definition (see the definition of "generic location" given by Achille Varzi and Roberto Casati ([11]: 120), although they plausibly invoke P-exact location rather than exact location):

\footnotetext{
${ }^{8}$ Antony Eagle [9] appeals to a similar argument to support the claim that exact location cannot be defined solely in terms of weak location.

${ }^{9}$ Eagle [10] defines an interesting notion of location in terms of weak location and mereological notions that, in Situation 1 but not in Situation 2, is coextensive with the notion of exact location. An object is located in Eagle's sense at a region $\mathrm{R}$ iff $\mathrm{df}_{\mathrm{f}}$ (i) $\mathrm{R}$ contains and is filled by the object, and (ii) no proper sub-region of $\mathrm{R}$ has that property. A region contains an object iff $f_{\mathrm{df}}$ each part of the object is weakly located at a part of the region,

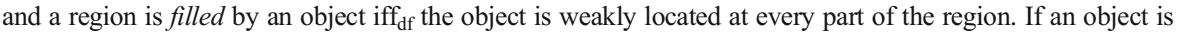
mereologically simple, then it fills a region only if the region contains it, and therefore such an object is located in Eagle's sense at a region $\mathrm{R}$ iff (i) the object fills $\mathrm{R}$ and (ii) it does not fill any proper sub-region of R. As a consequence, in both Situation 1 and Situation 2, the occupier is located in Eagle's sense at R6 and R7 but not at R6 + R7. Hence, as announced, Eagle's notion is coextensive with exact location in Situation 1 but not in Situation 2.
} 
- $\mathrm{x}$ we-@ $\mathrm{R}$ iff $\mathrm{df}_{\mathrm{f}}$ there is an object $\mathrm{x}^{*}$ and a region $\mathrm{R}^{*}$ such that $\mathrm{x}^{*} \leq \mathrm{x}, \mathrm{R}^{*} \leq \mathrm{R}$ and $\mathrm{X}^{*}$ is exactly located at $\mathrm{R}^{*}$.

One cannot derive Exactness from this definition, and to this extent the definition is better than the previous one. Yet one can derive something dangerously close: every object that is weakly located has a part that is exactly located. For objects that have no proper parts, this principle boils down to Exactness. Hence, even though Exactness in its unrestricted form cannot be derived, the requirement of NEUTRALITY gives us a reason to be unhappy about the proposed definition if it is supposed to be part of a general theory of location. Be that as it may, it can be shown that the theory entails No Spanners and hence is not neutral. For assume No Spanners is false. Then there is an object $\mathrm{x}$ and a region $\mathrm{R}$ with proper parts at which $\mathrm{x}$ is exactly located, such that there is no part $\mathrm{y}$ of $\mathrm{x}$ and no proper part $\mathrm{S}$ of $\mathrm{R}$ such that $\mathrm{y}$ is exactly located at $\mathrm{S}$. Let $\mathrm{T}$ be a proper part of $\mathrm{R}$. Since $\mathrm{x}$ is exactly located at $\mathrm{R}, \mathrm{T}$ is not completely free of $\mathrm{x}$ and hence (remember the informal gloss on weak location) $\mathrm{x}$ is weakly located at $\mathrm{T}$. By the proposed definition of weak location, there should then be an object $\mathrm{y}$ and a region $\mathrm{S}$ such that $\mathrm{y} \leq \mathrm{x}, \mathrm{S} \leq \mathrm{T}$ and $\mathrm{y}$ is exactly located at $\mathrm{S}$. Since $\mathrm{S} \leq \mathrm{T}$ and $\mathrm{T}$ is a proper part of $\mathrm{R}, \mathrm{S}$ is also a proper part of $\mathrm{R}$. But by hypothesis, this cannot be.

Thus, the previous definitions of weak location in terms of exact location and mereological notions rule out NEUTRALITY. Here is an argument to the effect that no NEUTRAL theory of location can define weak location solely in terms of exact location and mereological notions. Consider the two Parsonsian situations depicted in Fig. 3 (see the argument that Exactness is not conceptually necessary in §2). In Situation 3, R8 is the maximal region of a gunky space none of whose regions are point-shaped, $\mathrm{R} 9$ is a proper part of R8, and $\Gamma$ is a point-shaped material object, the only occupier of the space, that is weakly located at R9. Situation 4 is just like Situation 3 except that $\Gamma$ is not weakly located at R9 (while still being weakly located at R8). I contend that a NEUTRAL theory of location should leave room for such situations. These two situations are exactly alike in terms of exact location: in both there is a unique occupier, and it is exactly located nowhere. They are also mereologically alike. Since they differ in terms of weak location, it follows that weak location cannot be defined in terms of exact location and mereological notions.

In the light of the previous discussion, it is natural to contemplate the idea of having both exact location and weak location as primitive in our theory. However, as Eagle [9] rightly points out, such a theory would be unappealing, because exact and weak location are necessarily connected in many ways (e.g. necessarily, an object is weakly located at any region that overlaps any of the object's exact locations) and accepting a theory of that sort would force us to take these necessary connections to be brute. ${ }^{10}$ The point can be generalised. The various locational notions one can think of are necessarily connected in many ways, and there is accordingly a risk that deciding to take more than one as primitive will commit one to multiplying brute necessities. Thus, we should try our best to come up with a satisfactory theory framed in terms of a single primitive.

But is this at all possible? The theories surveyed so far took either P-exact location, or exact location, or weak location as sole primitive. Which other locational notion could possibly give us what we want?

\footnotetext{
${ }^{10}$ Matt Leonard [12] makes the same point, although he does not distinguish between exact location and Pexact location.
} 


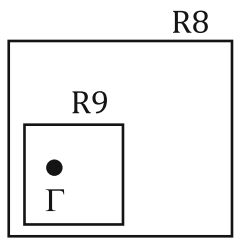

Situation 3

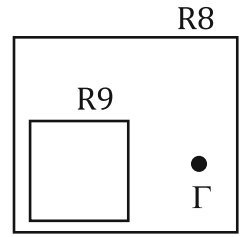

Situation 4

Fig. 3 A point-shaped object in a gunky space

The only theory I know of that takes a different locational notion as primitive has been put forward by Roberto Loss. In [13], he devises a theory of location based on pervasive location - to be fully accurate: based on a collective notion of pervasive location, connecting one or several objects to a region, which reduces to standard pervasive location when the "collection" comprises only one object. He defines both exact location and weak location in terms of his locational primitive and mereological notions. We do not need to go into the details to see that his theory is not NEUTRAL. Situations 1 and 2 can be used to show this. Given that each situation features only one object, in each situation Loss' primitive locational relation is coextensive with standard pervasive location. As we saw, the situations do not differ mereologically. They do not differ in terms of pervasive location either: in each situation, the object pervades every region. And yet, as we saw, they differ in terms of exact location. Situations 3 and 4 can also be used to show that Loss' theory is not NEUTRAL. The situations do not differ mereologically, and they do not differ in terms of pervasive location either: in each situation, the object pervades no region at all. Yet they differ in terms of weak location. $^{11}$

Before moving on to the next section, let me expand the definitional points I have made based on Situations 1 and 2 and Situations 3 and 4. Situations 1 and 2 do not differ mereologically, nor do they differ in terms of weak, pervasive, P-exact or P-entire location: in each situation, the object is weakly and pervasively located everywhere and it is P-exactly and P-entirely located at R6 + R7 and only at that region. Yet they differ in terms of both exact and entire location: in Situation 1, the object is exactly and hence entirely located at R6, whereas in Situation 2, the object is not entirely, and hence not exactly, located at that region. This implies the following definitional fact:

\footnotetext{
${ }^{11}$ In [14], Loss modifies the theory by starting with a different notion of pervasive location, the notion of "basic filling", and suggests that it can be used, together with mereological notions, to define exact location in such a way that Functionality is not automatically validated. Loss' informal gloss on basic filling is this: a (possibly one-membered) plurality of objects basically fills region $\mathrm{R}$ iff (i) no part of $\mathrm{R}$ is free of all the members of the plurality and (ii) the size of $\mathrm{R}$ is not bigger than the sum of the sizes of all the members of the plurality. (The appeal to size makes the gloss, just like the gloss on exact location given by Gilmore (see $\S 1$ ), not completely neutral on the nature of the space of regions, but I will not dwell on that.) I guess that Loss would have it that Situations 1 and 2 differ in terms of basic filling, on the grounds that in Situation 1 the occupier basically fills only R6 and R7, while in Situation 2 it also basically fills R6 + R7. If this is correct, then one cannot use these situations to argue that Loss' theory is not NEUTRAL. However, Situations 3 and 4 can be used as before to show this, since by hypothesis in these situations $\Gamma$ is the only occupier and it basically fills no region. (The assumption that $\Gamma$ is the only occupier is crucial. Loss allows for regions to be themselves occupiers, and, as a reviewer correctly points out, he would have it that in Situation 3 but not in Situation 4, the plurality consisting of $\Gamma$ and R9 basically fills R9. On this account, the two situations do differ in terms of basic filling. However, as the reviewer also correctly points out, the assumption that regions (alone or together with other entities) basically fill themselves is highly controversial.)
} 
- In a NeUTRAL theory, one cannot define exact location or entire location solely in terms of mereological notions and one of weak location, pervasive location, P-exact location and P-entire location.

Situations 3 and 4 do not differ mereologically, nor do they differ in terms of exact, pervasive or P-exact location: in each situation, the object is exactly, pervasively and Pexactly located nowhere. Yet they differ in terms of weak, entire and P-entire location: in Situation 3, the object is located in the three senses at R9, whereas in Situation 4, the object is not located, in any of the three senses, at that region. This implies the following definitional fact:

- In a NeUtRal theory, one cannot define weak location, entire location or P-entire location solely in terms of mereological notions and one of exact location, pervasive location and P-exact location.

These facts show that in a NEUTRAL theory, entire location cannot be defined in terms of any of the other core relations (and mereology). Is this also true of another core notion? One cannot derive a positive answer from the facts stated above. I believe that the answer is negative: the theory that I put forward in the next section defines in terms of entire location all the other core relations, and, as I ague there, it is NEUTRAL.

\section{A Theory Based on Entire Location}

In this section I lay down some basic principles and definitions of my theory of location based on the relation of being entirely located at, and I argue that the theory is NEUTRAL. I develop the theory further in the next three sections.

Remember the informal characterisations of entire location and P-entire location:

- $\mathrm{x}$ is entirely located at $\mathrm{R}$ iff $\mathrm{x}$ lies within $\mathrm{R}$.

- $\mathrm{x}$ is $\mathrm{P}$-entirely located at $\mathrm{R}$ iff $\mathrm{R}$ is not completely free of $\mathrm{x}$, and all the regions disjoint from $\mathrm{R}$ are completely free of $\mathrm{x}$.

It is crucial to bear in mind the contrast between these two notions in order to correctly grasp the first one. Suppose $\mathrm{x}$ is exactly located at two disjoint regions $\mathrm{R}$ and $\mathrm{S}$. Then $\mathrm{x}$ is entirely located at both, and also at their fusion [assuming they have one]: $\mathrm{x}$ lies within $\mathrm{R}$, within $\mathrm{S}$ and within $\mathrm{R}+\mathrm{S}$. By contrast, $\mathrm{x}$ is not $\mathrm{P}$-entirely located at $\mathrm{R}: \mathrm{S}$ is disjoint from $\mathrm{R}$ and is not completely free of $\mathrm{x}$. Likewise, $\mathrm{x}$ is not P-entirely located at $\mathrm{S}$. Whether $\mathrm{x}$ is P-entirely located at $\mathrm{R}+\mathrm{S}$ depends on what happens outside this region: if all the regions disjoint from $\mathrm{R}+\mathrm{S}$ are completely free of $\mathrm{x}$, then $\mathrm{x}$ is $\mathrm{P}$ entirely located at $\mathrm{R}+\mathrm{S}$; if not, not. These points can be illustrated by invoking Situation 1: $\Delta$ is entirely located at R6, R7 and R6 + R7, and it is P-entirely located at $\mathrm{R} 6+\mathrm{R} 7$ and at no other region.

One of my aims in this section is to define both exact location and weak location in terms of entire location. Another aim is to also define the other core locational relations introduced in the previous section: pervasive, P-entire and P-exact location. 
Any theory of location must presuppose a mereology of regions. I will follow the previous notational conventions and use $\leq$ for (proper-or-improper) parthood and $\circ$ for overlap, and I will use $<$ for proper parthood and $\imath$ for disjointness. The last three relations are defined in the usual way in terms of $\leq$. I will assume that parthood is reflexive, antisymmetric and transitive. "General Extensional Mereology" (GEM), often considered as the "standard" theory of part-whole, can be axiomatized by adding to this basis the following two principles (by 'entity', I mean anything that is intended to be in the domain of the quantifiers - which, for certain purposes, may just be the regions of a given space of regions):

\section{Strong Supplementation}

For all entities $\mathrm{X}$ and $\mathrm{Y}$, if not $\mathrm{X} \leq \mathrm{Y}$, then for some entity $\mathrm{Z}$ such that $\mathrm{Z} \imath \mathrm{Y}, \mathrm{Z} \leq$ $\mathrm{X}$.

\section{Unrestricted Composition}

Given any collection of entities $\mathcal{C}$, there is an entity $\mathrm{Z}$ that is a fusion of the members of $\mathcal{C}$, i.e. such that for all entities $\mathrm{Y}, \mathrm{Y} \circ \mathrm{Z}$ iff $\mathrm{Y} \circ \mathrm{X}$ for some $\mathrm{X} \in \mathcal{C}$.

Given Strong Supplementation, the members of any given collection of entities then have a unique fusion, so we can talk of the fusion of these entities. Assuming GEM for regions right from the start would be too much. A theory of location should leave room for the possibility that the space of regions is junky, ${ }^{12}$ i.e., that any of its regions has proper super-regions. Yet such spaces are incompatible with Unrestricted Composition. By contrast, I will assume that the spaces of regions of relevance to us obey Strong Supplementation and hence that the mereology of regions is extensional (given Strong Supplementation, if an entity $\mathrm{X}$ has proper parts, then for all $\mathrm{Y}, \mathrm{X}=\mathrm{Y}$ iff $\mathrm{X}$ and $\mathrm{Y}$ have the same proper parts). It would in principle be possible to work with weaker mereologies, but I leave the exploration of the corresponding theories to possible future work. Strong Supplementation for regions is not a very substantial principle anyway, so taking it on board will not be a problem-or so I hope.

Location and mereological relations between regions are connected in various ways. A useful guide to these connections is what one may call, for lack of a better label, 'the mereological conception of location'-a conception that naturally goes with supersubstantivalism, the controversial view that occupiers of physical space or spacetime are themselves regions of space or spacetime. On that conception, the following biconditionals hold:

(B1) x ex-@R iff x P-ex-@R iff $x=R$.

(B2) x we-@R iff $x \circ \mathrm{R}$.

(B3) x pe-@ $\mathrm{R}$ iff $\mathrm{R} \leq \mathrm{x}$.

(B4) x en-@ R iff x P-en-@ R iff $x \leq R$.

These biconditionals entail many other connections between locational and mereological notions. Of course, these connections should not be blindly included in a general theory of location: for instance, (B1) entails both Functionality and Exactness, and a NEUTRAL theory of location should not entail these principles. When used as a

\footnotetext{
$\overline{12}$ The word, now standardly used, is from Jonathan Schaffer [15]. Parsons [2] uses 'knuggy' instead.
} 
guide to the formulation of a general theory of location, the mereological conception of location should be used with care.

An example of a principle derived from that conception that one can safely take for granted is the following, which I take as axiomatic (here and below, I keep on using variables ' $\mathrm{x}$ ', ' $y$ ', $\ldots$ for occupiers and variables ' $R$ ', ' $S$ ', $\ldots$ for regions):

\section{[Axiom] Monotonicity}

If $\mathrm{x}$ en-@ $\mathrm{R}$ and $\mathrm{R} \leq \mathrm{S}$, then $\mathrm{x}$ en-@ S.

It straightforwardly follows from (B4) and the transitivity of parthood. Another example that I also take as axiomatic is a principle that involves weak location, which I will define in a moment:

\section{[Axiom] Locational Strong Supplementation}

If $\mathrm{x}$ en-@ $\mathrm{S}$ for some region $\mathrm{S}$ and not $\mathrm{x}$ en-@ $\mathrm{R}$, then there is a region $\mathrm{R}^{*}$, $\mathrm{R}$ such that xwe-@ R*.

The principle follows from (B2) and (B4) and the following mereological principle, which is equivalent to Strong Supplementation:

For all entities $\mathrm{X}$ and $\mathrm{Y}$, if not $\mathrm{X} \leq \mathrm{Y}$, then for some entity $\mathrm{Z}$ such that $\mathrm{Z}, \mathrm{Y}, \mathrm{Z} \circ \mathrm{X}$.

A third example is:

\section{[Axiom] Localisation}

There is a region $\mathrm{R}$ such that $\mathrm{x}$ en-@ $\mathrm{R}$.

which follows from (B4) and the reflexivity of parthood.

Let me now turn to the task of defining exact location and weak location. For exact location, I propose the following definition:

\section{[Definition] Exact location}

$\mathrm{x}$ ex-@ $\mathrm{R}$ iff $\mathrm{df}$ x en-@ $\mathrm{R}$ and there is no region $\mathrm{R}^{*}$ such that $\mathrm{R}^{*}<\mathrm{R}$ and $\mathrm{x}$ en-@ R*.

The definition says that an exact location of an occupier is an entire location of that occupier which is minimal for proper parthood. This sounds just right to me. The alert reader will have noticed that the definition rules out what Costa and Calosi [16] call "nested multilocation", i.e. cases where an object x is exactly located at two regions such that one is a proper part of the other. But I do not take this to be a problem (see the discussion in $§ 5){ }^{13}$

For weak location, my proposal is:

\footnotetext{
${ }^{13}$ In his Ph.D. dissertation Being in Time: A Theory of Persistence and Temporal Location (2014), Damiano Costa suggests a definition that is similar, but which entails Functionality. The definition is: $\mathrm{x}$ ex-@ $\mathrm{R}$ iff $\mathrm{df}_{\mathrm{x}}$ en-@ $\mathrm{R}$ and for all regions $\mathrm{R}^{*}$ such that $\mathrm{x}$ en-@ $\mathrm{R}^{*}, \mathrm{R} \leq \mathrm{R}^{*}$.
} 


\section{[Definition] Weak location}

$\mathrm{x}$ we-@ $\mathrm{R}$ iff $\mathrm{df}_{\mathrm{f}}$ there is a region $\mathrm{S}$ such that $\mathrm{x}$ en-@ $\mathrm{S}$ and for all regions $\mathrm{R} * \leq \mathrm{S}$ such that $\mathrm{x}$ en-@ $\mathrm{R}^{*}, \mathrm{R}^{*} \circ \mathrm{R}$.

Crucially, I did not suggest the following simpler definition:

- $\mathrm{x}$ we-@ $\mathrm{R}$ iff $\mathrm{df}_{\mathrm{f}}$ for all regions $\mathrm{R}^{*}$ such that $\mathrm{x}$ en-@ $\mathrm{R}^{*}, \mathrm{R} \circ \mathrm{R}^{*}$.

The reason is that the simpler definition predicts wrong results in cases of multiple exact location. For suppose that object $\Omega$ is exactly located at two disjoint regions $\mathrm{T}$ and $\mathrm{R}^{*}$ and suppose region $\mathrm{R}$ overlaps $\mathrm{T}$ but not $\mathrm{R}^{*}$, as in the situation represented by Fig. 4 (where $\Omega$ is represented by the grey area). We want to say that $\Omega$ is weakly located at R. But the simpler definition predicts that this is not the case: given that $\Omega$ is exactly located at $\mathrm{R}^{*}, \Omega$ is entirely located at $\mathrm{R}^{*}$, but by hypothesis $\mathrm{R}$ does not overlap $\mathrm{R}^{*}$. By contrast, my definition of weak location predicts the correct result: region $\mathrm{S}$ represented in Fig. 4 satisfies the condition expressed in the definiens.

My definition of exact location is compatible with Functionality, and also with its negation. In particular, the view that there is the kind of temporal multilocation exemplified by enduring objects described in $\$ 2$ is clearly compatible with the definition, and the same goes for the view that there is the kind of spatial multilocation exemplified by enduring time travellers described there.

My definitions of exact location and weak location are also clearly compatible with Exactness, and also with its negation. Consider for instance a scenario with a pointshaped object in a gunky space as described in $\S 2$. The point is entirely located at many regions. Yet there is no minimal region at which it is entirely located. Hence, by the proposed definition of exact location, the object has no exact location. But since it is entirely located, it is weakly located. Hence, my definitions predict that Exactness fails in scenarios of the kind under consideration.

Finally, my definition of exact location is compatible both with No Spanners and with its negation. That it is compatible with the negation of the principle could be illustrated using the scenario of the argument from homes from $\S 2$, but invoking Situation 2 from $\S 3$ is more straightforward. In this situation, $\Sigma$ is mereologically simple. It is entirely located at R6 + R7 and at no other region, and therefore it is, by my definition, exactly located at R6 + R7. Hence, $\Sigma$ is, by the definition, an extended simple and hence a spanner.
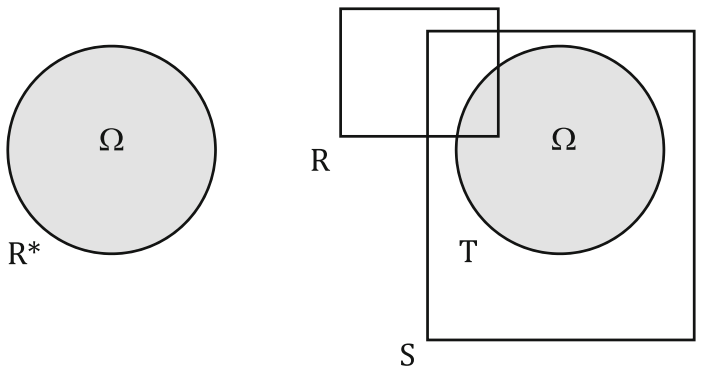

Fig. 4 Weak location and multiply exactly located objects 
These points establish that the theory of location that I have just put forward is NEUTRAL. The additions to the theory that I will suggest in this and the next sections, I take it, will not make it lose this feature.

Let me now turn to the task of defining the remaining core locational relations. Consider the relation of strong pervasive location, which I define as follows:

\section{[Definition] Strong pervasive location}

$\mathrm{x}$ S-pe-@ $\mathrm{R}$ iff $\mathrm{df}_{\mathrm{f}}$ there is a region $\mathrm{S}$ such that $\mathrm{x}$ en-@ $\mathrm{S}$ and for all regions $\mathrm{R}^{*} \leq$ $\mathrm{S}$ such that $\mathrm{x}$ en-@ $\mathrm{R} *, \mathrm{R} \leq \mathrm{R}^{*}$.

It is tempting to suggest that pervasive location just is strong pervasive location. However, the notion so defined is close to but not identical with the target notion. Pervasive location is subject to an additivity principle that holds as a matter of conceptual necessity: if an object is pervasively located at two regions and these regions have a fusion $\mathrm{R}$, then the object is pervasively located at $\mathrm{R}$. Additivity for strong pervasive location fails in some conceptually possible situations. For consider again the situation depicted in Fig. 4, and assume that $\mathrm{R}^{*}$ and $\mathrm{T}$ have a fusion $\mathrm{R}^{*}+\mathrm{T}$. It is an immediate consequence of my definition of exact location and of the proposed definition of strong pervasive location that since $\Omega$ is exactly located at both $\mathrm{R}^{*}$ and $\mathrm{T}$, $\Omega$ is also strongly pervasively located at these regions. Now $\Omega$ is not strongly pervasively located at $\mathrm{R}^{*}+\mathrm{T}$, because any region at which $\Omega$ is entirely located and which contains $\mathrm{R}^{*}+\mathrm{T}$ contains a region at which $\Omega$ is entirely located and which contains only a proper part of the fusion. ${ }^{14}$

Let us say that a collection of regions $\mathscr{R}$ covers a region $\mathrm{R}$ iff $\mathrm{df}_{\mathrm{df}}$ every region that overlaps $\mathrm{R}$ overlaps some member of $\mathscr{R}$. (If GEM is assumed, $\mathscr{R}$ covers $\mathrm{R}$ iff $\mathrm{R}$ is a part of the fusion of the members of $\mathscr{R}$.) The previous considerations suggest that we should adopt the following definition:

\section{[Definition] Pervasive location}

$\mathrm{x}$ pe-@ $\mathrm{R}$ iff $\mathrm{df}_{\mathrm{f}}$ there is a non-empty collection of regions $\mathscr{R}$ such that (i) x Spe-@ $\mathrm{R}^{*}$ for all $\mathrm{R}^{*} \in \mathscr{R}$ and (ii) $\mathscr{R}$ covers $\mathrm{R}$.

Contrary to strong pervasive location, pervasive location does obey the additivity principle. Strong pervasive location is not just a notion that is useful to define pervasive location, it connects in an interesting way exact location and entire location:

\section{[Proposition 1]}

x ex-@R iff x en-@R and x S-pe-@ R.

PROOF Left-to-right. Suppose x ex-@ R. Then (i) x en-@ R and (ii) there is no region $\mathrm{R}^{*}$ such that $\mathrm{R}^{*}<\mathrm{R}$ and $\mathrm{x}$ en-@ $\mathrm{R}^{*}$. Take any region $\mathrm{R}^{*}$ such that $\mathrm{R}^{*} \leq \mathrm{R}$ such that $\mathrm{x}$ en-@ $\mathrm{R}^{*}$. By (ii) we know that not $\mathrm{R}^{*}<\mathrm{R}$. Hence $\mathrm{R}^{*}=\mathrm{R}$, and so $\mathrm{R} \leq \mathrm{R} *$. It follows that x S-pe-@ R. Right-to-left. Suppose x en-@ R and x S-pe-@ R. Let S be such that (i) $\mathrm{x}$ en-@ $\mathrm{S}$ and (ii) for all regions $\mathrm{R}^{*} \leq \mathrm{S}$ such that $\mathrm{x}$ en-@ $\mathrm{R}^{*}, \mathrm{R} \leq \mathrm{R}^{*}$. We have in

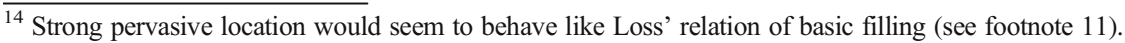


particular that $\mathrm{R} \leq \mathrm{S}$. Assume for reductio that not $\mathrm{x}$ ex-@ $\mathrm{R}$. Then let $\mathrm{R} *$ be such that $\mathrm{R}^{*}<\mathrm{R}$ and $\mathrm{x}$ en-@ $\mathrm{R}^{*}$. Then $\mathrm{R}^{*} \leq \mathrm{S}$. By (ii) we should then have $\mathrm{R} \leq \mathrm{R} *$. But this is impossible since $\mathrm{R} *<\mathrm{R}$.

Let me finally deal with P-exact and P-entire location. I suggest the following definitions:

\section{[Definition] P-entire location}

x P-en-@ R iff df $\mathrm{x}$ we-@ R and there is no region $\mathrm{R}^{*}$, R such that $\mathrm{x}$ we-@ R*.

\section{[Definition] P-exact location}

x P-ex-@R iff df $x$ P-en-@ R and x pe-@ R.

The definition of P-entire location is modelled on the informal characterisation of the notion given in $\$ 3$. Interestingly, given Locational Strong Supplementation, one can derive the following proposition, which makes the comparison between P-entire location and entire location more straightforward:

\section{[Proposition 2]}

$\mathrm{x}$ P-en-@ $\mathrm{R}$ iff $\mathrm{x}$ en-@ $\mathrm{R}$ and there is no region $\mathrm{R}^{*}$, $\mathrm{R}$ such that $\mathrm{x}$ we-@R*.

The definition of P-exact location mirrors the connection between exact, entire and strong pervasive location expressed in Proposition 1. As I stressed in $\S 3$, the biconditional corresponding to this definition is taken for granted by Parsons [2].

Entire location and the locational notions I defined in terms of it, minus weak location, are related as in Fig. 5, where each arrow represents a relation of entailment. These links follow from Propositions 1 and 2 and the definitions of pervasive location and of P-exact location.

It can be shown that weak location is entailed both by entire location and by pervasive location:

\section{[Proposition 3]}

If either x en-@R or x pe-@ R, then xwe-@R.

PROOF (1) Suppose x en-@ R. Since for every region $\mathrm{R}^{*} \leq \mathrm{R}, \mathrm{R}^{*} \circ \mathrm{R}$, we have $\mathrm{x}$ we-@ R. (2) Supposex pe-@R and let. $\mathscr{R}$ be a nonempty collection of regions such that (i) x S-pe-@ $\mathrm{R}^{*}$ for all $\mathrm{R}^{*} \in \mathscr{R}$ and (ii) $\mathscr{R}$ covers $\mathrm{R}$. Since $\mathscr{R}$ covers $\mathrm{R}$, there is at least one region $\mathrm{R}^{* *}$ $\in \mathscr{R}$ such that $\mathrm{R} \circ \mathrm{R}^{* *}$. By (i), $\mathrm{x}$ S-pe-@ $\mathrm{R}^{* *}$, and so there is a region $\mathrm{S}$ such that $\mathrm{x}$ en-@ $\mathrm{S}$

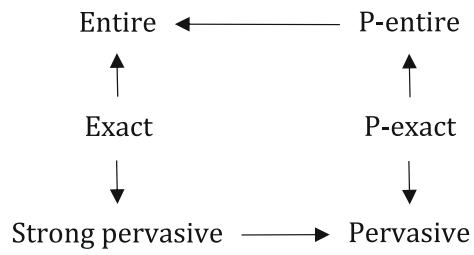

Fig. 5 Entailments 
and for all regions $\mathrm{R}^{*} \leq \mathrm{S}$ such that $\mathrm{x}$ en- @ $\mathrm{R}^{*}, \mathrm{R}^{* *} \leq \mathrm{R}^{*}$. Since $\mathrm{R} \circ \mathrm{R} * *$, it follows that $\mathrm{x}$ we-@ R.

As a consequence, all the relations depicted in Fig. 5 entail weak location. Note that there is no link of entailment between exact and P-exact location. Situation 1 provides a counterexample for each direction: $\Delta$ is exactly but not P-exactly located at R6, and it is P-exactly but not exactly located at R6 + R7. As we will see in the next section, banning multilocation results in a collapse of the relations on the right in Fig. 5 to the corresponding relations on the left.

\section{Being Multilocated}

As I stressed in the previous section, my definition of exact location rules out nested multilocation. A standard example used to illustrate the possibility of nested multilocation invokes immanent universals (see [16]: §5): suppose a given exactly located surface is uniformly red; then granted that immanent universals are exactly located where their exemplifiers are exactly located, the immanent universal Redness will be exactly located at many overlapping sub-regions of the region at which the surface is exactly located and some of these sub-regions are proper parts of others. Examples invoking material objects instead of universals can be found in Gilmore [18], Effingham \& Robson [17], and Kleinschmidt [20].

Some might take this consequence of my definition to count against it: surely, some might argue, nested multilocation is conceptually possible, and therefore any good theory of location should leave room for it. I am not impressed by this argument. It presupposes that any good theory of location should leave room for any conceptual possibility - that it should be "absolutely neutral", in the sense introduced at the end of $\S 2$. But why should we accept this? It might be replied that even though it is not true that any good theory of location should leave room for any conceptual possibility, it should at least leave room for any conceptual possibility that is not "too remote", i.e. not too hard to conceive. Maybe. But I rejoin that I find nested multilocation particularly hard to conceive. More generally, I find it particularly hard to conceive of cases of exact location at distinct but overlapping regions. ${ }^{15}$ For the sake of definiteness, think of occupiers of 3D space. Although many philosophers believe that distinct entities can share their exact (spatial) location (think of the statue / lump of clay example), it is highly implausible to hold that there are no limits whatsoever in which objects can have overlapping exact location. Objects of the same kind, it is sometimes said, cannot share their exact location. Likewise (barring issues stemming from vagueness), two cats (say) cannot have overlapping exact locations. These considerations concern distinct entities, and therefore do not directly bear on the idea multiply exactly located objects. However, it seems to me that the idea of there being a cat exactly located at distinct overlapping spatial regions is just as counterintuitive as the idea of there being two cats exactly located at overlapping spatial regions. I do not have any firm view about the conditions under it is possible for distinct objects to have overlapping exact locations, if this is at all possible - relative to location in $3 \mathrm{D}$ space, but also in general. Yet it seems

\footnotetext{
${ }^{15}$ But see Eagle [21] for a defence of the view that such cases, including cases of nested multilocation, are conceptually possible.
} 
to me acceptable to ignore or even reject the possibility that a single object has distinct but overlapping exact locations.

Rejection of this possibility can be secured by adopting the following principle:

\section{[Possible axiom] Restricted Multilocation}

If $x$ is entirely located at overlapping regions $\mathrm{R}$ and $\mathrm{S}$, then either (i) there is a region $\mathrm{T}$ such that both $\mathrm{T} \leq \mathrm{R}$ and $\mathrm{T} \leq \mathrm{S}$ at which $\mathrm{x}$ is entirely located, or (ii) there are regions $\mathrm{R}^{*} \leq \mathrm{R}$ and $\mathrm{S}^{*} \leq \mathrm{S}$ that do not overlap such that $\mathrm{x}$ is entirely located at both $\mathrm{R}^{*}$ and $\mathrm{S}^{*}$.

One can indeed readily verify that this principle together with my definition of exact location rules out the possibility for an object to have distinct overlapping exact locations. I will not take this principle as an axiom of the theory. Rather, I mention it as a principle that can be accepted as an axiom for an extension of the theory. For the reasons given above, I am happy to extend the theory in this way, but some might prefer to do without it, on the grounds that while nested multilocation is problematic, the other cases of exact location at distinct but overlapping regions are not.

Multilocation is usually understood as exact location at more than one region. If one leaves room for failures of Exactness, one should also leave room for situations in which some multilocated objects fail to have exact locations. Yet how is multilocation to be defined if this is to make any sense? Here is a natural suggestion that I am happy to adopt:

\section{[Definition] Being multilocated}

An object $\mathrm{x}$ is multilocated iff $_{\mathrm{df}} \mathrm{x}$ is entirely located at a region $\mathrm{R}$ and weakly located at a region disjoint from $\mathrm{R}$.

It directly follows from my definitions of exact and weak location that if an object has distinct exact locations, then it is multilocated in this sense. The converse fails in general, but as I will show in the next section, it holds if a principle stronger than Exactness holds (see Proposition 9). If Restricted Multilocation is taken on board, then it can be established that an object $\mathrm{x}$ is multilocated iff it is entirely located at two disjoint regions.

Consider the following principle:

\section{Focus}

No object is multilocated.

We have:

\section{[Proposition 4]}

Focus entails Functionality.

PROOF Suppose x ex-@ $\mathrm{R}$ and $\mathrm{x}$ ex-@ $\mathrm{R}^{*}$ with $\mathrm{R}$ distinct from $\mathrm{R}^{*}$. Then either not $\mathrm{R} \leq$ $\mathrm{R}^{*}$ or not $\mathrm{R} * \leq \mathrm{R}$. Let us deal only with the first case (the second case is symmetric). By Strong Supplementation, there is a region $\mathrm{S}$ < $\mathrm{R}^{*}$ such that $\mathrm{S} \leq \mathrm{R}$. Since $\mathrm{x}$ ex-@ R and $\mathrm{S} \leq \mathrm{R}, \mathrm{x}$ we-@S. 
The converse fails. In a universe where space is gunky and none of its regions is point-shaped, all occupiers of space are point-shaped material objects and some occupier of space is entirely located at two disjoint spatial regions, Functionality (vacuously) holds but Focus is violated. Such universes are surely conceptually possible.

My definition of P-en-@ is the same as the definition in Parsons\#2. Given Focus, one can derive the biconditionals corresponding to the other two definitions in Parsons\#2:

\section{[Proposition 5]}

If Focus holds, then:

(a) $\mathrm{x}$ pe-@ $\mathrm{R}$ iff for all regions $\mathrm{R}^{*}$, if $\mathrm{R}^{*} \circ \mathrm{R}$, then $\mathrm{x}$ we-@ $\mathrm{R} *$;

(b) x P-ex-@ $\mathrm{R}$ iff for all regions $\mathrm{R}^{*}, \mathrm{x}$ we-@ $\mathrm{R} *$ iff $\mathrm{R}^{*} \circ \mathrm{R}$.

PROOF (a) Left-to-Right. Suppose x pe-@ R and let $\mathscr{R}$ be a non-empty collection of regions such that (i) x S-pe-@ $\mathrm{R}^{* *}$ for all $\mathrm{R}^{* *} \in \mathscr{R}$ and (ii) $\mathscr{R}$ covers $\mathrm{R}$. Assume $\mathrm{R}^{*} \mathrm{O}$ $\mathrm{R}$. Then for some $\mathrm{R}^{* *} \in \mathscr{R}, \mathrm{R}^{* *} \circ \mathrm{R}^{*}$. We have $\mathrm{x}$ S-pe-@ $\mathrm{R}^{* *}$ and therefore a region $\mathrm{S}$ such that $\mathrm{x}$ en-@ $\mathrm{S}$ and for all regions $\mathrm{S} * \leq \mathrm{S}$ such that $\mathrm{x}$ en-@ $\mathrm{S} * \mathrm{R} * * \leq \mathrm{S}^{*}$. Since $\mathrm{R}^{* *} \circ \mathrm{R}^{*}$, we then have that for all regions $\mathrm{S}^{*} \leq \mathrm{S}$ such that $\mathrm{x}$ en-@ $\mathrm{S}^{*}, \mathrm{~S}^{*} \circ \mathrm{R}^{*}$. Hence, xwe-@ R*. Right-to-left. Suppose not x pe-@ R. Then not x S-pe-@ R. By Localisation, there is a region S such that x en-@ S. Since not x S-pe-@ R, it follows that there is a region $\mathrm{R}^{*} \leq \mathrm{S}$ such that $\mathrm{x}$ en-@ $\mathrm{R}^{*}$ and not $\mathrm{R} \leq \mathrm{R}^{*}$. By Strong Supplementation, there is a region $\mathrm{R}^{* *}$ disjoint from $\mathrm{R}^{*}$ that is a part of $\mathrm{R}$ and hence that overlaps it. By Focus, not xwe-@ R**. (b) Suppose x P-ex-@ R. Then x P-en-@ R and x pe-@ R. Let R* be a region. Suppose xwe-@ R*. Sincex P-en-@ R, R* o R. Conversely, suppose R* $\circ \mathrm{R}$. Since x pe-@ R, there is a non-empty collection of regions $\mathscr{R}$ such that (i) x S-pe-@ $\mathrm{R}^{* *}$ for all $\mathrm{R}^{* *} \in \mathscr{R}$ and (ii) $\mathscr{R}$ covers $\mathrm{R}$. Then $\mathrm{R}^{*}$ overlaps some $\mathrm{R}^{* *} \in \mathscr{R}$. Given that x S-pe-@ $\mathrm{R}^{* *}$, it follows that $\mathrm{x}$ we-@ $\mathrm{R}^{*}$. Suppose now that not x P-ex-@ R. Then (i) not x P-en-@ R or (ii) not x pe-@ R. Suppose first (i). Then either not x we-@ R or there is a region $\mathrm{R}^{*}$, R such that $\mathrm{x}$ we-@ $\mathrm{R} *$. In the first case, there is a region that overlaps $\mathrm{R}$ at which $\mathrm{x}$ is not weakly located (that region being $\mathrm{R}$ ), and in the second case we have the reverse, i.e. a region at which $\mathrm{x}$ is weakly located but which does not overlap R. Suppose now (ii). Then by (a) above there is a region at which $\mathrm{x}$ is not weakly located which overlaps $\mathrm{R}$.

Focus also allows one to derive the biconditional corresponding to the simple (inaccurate) definition of weak location I discussed in the previous section, as well as a similar principle about strong pervasive location:

\section{[Proposition 6]}

If Focus holds, then:

(a) $\mathrm{x}$ we-@ $\mathrm{R}$ iff for all regions $\mathrm{R}^{*}$ such that $\mathrm{x}$ en-@ $\mathrm{R}^{*}, \mathrm{R}^{*} \circ \mathrm{R}$;

(b) $\mathrm{x}$ S-pe-@ $\mathrm{R}$ iff for all regions $\mathrm{R}^{*}$ such that $\mathrm{x}$ en-@ $\mathrm{R} *, \mathrm{R} \leq \mathrm{R}^{*}$.

PROOF (a) The right-to-left direction follows from Localisation. The other direction follows from Focus. (b) The proof is almost identical to the proof of (a).

As announced at the end of the previous section, Focus makes some of the locational notions discussed there coextensive: 


\section{[Proposition 7]}

If Focus holds, then:

(a) x P-en-@ R iff x en-@ R;

(b) x P-ex-@R iff x ex-@ R;

(c) x S-pe-@ R iff x pe-@ R.

PROOF (a) By Proposition 2 and Focus. (b) Given Proposition 5 (b), it is enough to prove that $\mathrm{x}$ ex-@ R iff for all regions R*, x we-@ R* iff R* $\circ \mathrm{R}$. For the left-to-right direction, suppose $\mathrm{x}$ ex-@ R and let $\mathrm{R} *$ be a region. Suppose xwe-@ R*. Since x en-@ $\mathrm{R}$, by Focus we then have $\mathrm{R}^{*} \circ \mathrm{R}$. Conversely, suppose not $\mathrm{x}$ we-@ $\mathrm{R}^{*}$. By Proposition 6 (a), there is then a region $\mathrm{R}^{* *}$ such that $\mathrm{x}$ en-@ $\mathrm{R} * *$ and not $\mathrm{R} * 0$ $\mathrm{R} * *$. By Proposition 1, x S-pe-@ R, and so by Proposition 6 (b), R $\leq \mathrm{R} * *$. Since not R* $\circ \mathrm{R} * *$, it follows that not $\mathrm{R} * \circ \mathrm{R}$. For the right-to-left direction, suppose not $\mathrm{x}$ ex-@ $\mathrm{R}$. Then either not $\mathrm{x}$ en-@ $\mathrm{R}$ or there is a region $\mathrm{R} * *<\mathrm{R}$ such that $\mathrm{x}$ en-@ $\mathrm{R} * *$. In the first case, by Locational Strong Supplementation and Localisation, there is a region $\mathrm{R}^{*}$ such that $\mathrm{x}$ we-@ $\mathrm{R} *$ and not $\mathrm{R} * \mathrm{O}$. In the second case, there is a region $\mathrm{R} *$ such that $\mathrm{R} * 0$ $\mathrm{R}$ and not $\mathrm{x}$ we-@ $\mathrm{R}^{*}$ : take indeed for $\mathrm{R}^{*}$ any part of $\mathrm{R}$ that does not overlap $\mathrm{R}^{* *}$; Focus guarantees that $\mathrm{x}$ is not weakly located at $\mathrm{R}^{*}$. (c) The left-to-right direction is immediate. For the other direction, suppose that not x S-pe-@ R. By Proposition 6 (b), there is a region $\mathrm{R}^{*}$ such that $\mathrm{x}$ en-@ $\mathrm{R}^{*}$ and not $\mathrm{R} \leq \mathrm{R}^{*}$. By Strong Supplementation, there is a part $\mathrm{R}^{* *}$ of $\mathrm{R}$ disjoint from $\mathrm{R}^{*}$. By Focus, then, not $\mathrm{x}$ we-@ $\mathrm{R}^{* *}$. By Proposition 5 (a), it follows that not pe-@ R.

\section{Being Inexact}

If Focus is not assumed to hold, Exactness may be a "local" matter: there are conceivable situations in which an object is exactly located at some region $\mathrm{R}$, entirely located at some disjoint region $\mathrm{S}$ and not exactly at any sub-region of $\mathrm{S}$. Think of a situation in which there is a point-shaped occupier, exactly located at a point-shaped region, and also entirely located at another region that is gunky and whose parts all fail to be point-shaped. Let me adopt the following definition:

\section{[Definition] Being inexact}

An object $\mathrm{x}$ is inexact iff $_{\mathrm{df}}$ for some region $\mathrm{R}$ such that $\mathrm{x}$ en-@ $\mathrm{R}$, there is no region $\mathrm{R}^{*} \leq \mathrm{R}$ such that $\mathrm{x}$ ex-@ $\mathrm{R}^{*}$.

The objects that are not inexact are said to be exact. The following principle rules out the situations described above:

\section{Exactitude}

No object is inexact.

By the definition of weak location, all objects that are weakly located somewhere are entirely located somewhere. Hence: 


\section{[Proposition 8]}

Exactitude entails Exactness.

The converse does not follow from the previous definitions and axioms. The latter are indeed compatible with situations involving a unique occupier, which is as in the previously described situation (point-shaped, exactly located at some region, and entirely located at some gunky region whose parts fail to be point-shaped): in such situations, Exactness is true but Exactitude is false.

\section{[Proposition 9]}

If $\mathrm{x}$ is exact, then $\mathrm{x}$ is multilocated iff $\mathrm{x}$ has distinct exact locations.

PROOF As I stressed in the previous section, the right-to-left direction is obvious. For the other direction, let $\mathrm{x}$ be both exact and multilocated. Since $\mathrm{x}$ is multilocated, it is entirely located at some region $\mathrm{R}$ and weakly located at some region $\mathrm{S}$ disjoint from $\mathrm{R}$. There is then a region $\mathrm{R}^{*}$ at which $\mathrm{x}$ is entirely located, such that given any $\mathrm{T} \leq \mathrm{R}^{*}$ at which $\mathrm{x}$ is entirely located, $\mathrm{T} \circ \mathrm{S}$. Since $\mathrm{x}$ is exact, there is some $\mathrm{U} \leq \mathrm{R}$ and some $\mathrm{U}^{*}$ $\leq \mathrm{R}^{*}$ such that $\mathrm{x}$ is exactly located at both $\mathrm{U}$ and $\mathrm{U}^{*}$. We then have $\mathrm{U}^{*} \circ \mathrm{S}$, and since $\mathrm{U} \leq \mathrm{R}$ and $\mathrm{S}$ ? $\mathrm{R}, \mathrm{U}$ and $\mathrm{U}^{*}$ are distinct.

As a corollary, we get:

\section{[Proposition 10]}

If Exactitude holds, then Focus and Functionality are equivalent.

We also have:

\section{[Proposition 11]}

If Exactitude holds, then:

(a) $\mathrm{x}$ we-@ $\mathrm{R}$ iff there is a region $\mathrm{R}^{*}$ such that $\mathrm{x}$ ex-@ $\mathrm{R}^{*}$ and $\mathrm{R}^{*} \circ \mathrm{R}$;

(b) $\mathrm{x}$ en-@ $\mathrm{R}$ iff there is a region $\mathrm{R}^{*}$ such that $\mathrm{x}$ ex- $@ \mathrm{R}^{*}$ and $\mathrm{R}^{*} \leq \mathrm{R}$;

(c) $\mathrm{x}$ S-pe-@ $\mathrm{R}$ iff there is a region $\mathrm{R}^{*}$ such that $\mathrm{x}$ ex-@ $\mathrm{R}^{*}$ and $\mathrm{R} \leq \mathrm{R}^{*}$.

PROOF (a) Suppose xwe-@ R. Let then $\mathrm{S}$ be such that $\mathrm{x}$ en- $@ \mathrm{~S}$ and for all regions $\mathrm{R}^{*}$ $\leq \mathrm{S}$ such that $\mathrm{x}$ en-@ $\mathrm{R}^{*}, \mathrm{R}^{*} \circ \mathrm{R}$. By Exactitude there is a region $\mathrm{S}^{*} \leq \mathrm{S}$ such that $\mathrm{x}$ ex-@ $\mathrm{S}^{*}$. We then have $\mathrm{S}^{*} \circ \mathrm{R}$. Conversely, assume that there is a region $\mathrm{R}^{*}$ such that $\mathrm{x}$ ex-@ $\mathrm{R} *$ and $\mathrm{R} * \circ \mathrm{R}$. Consider then a region $\mathrm{R}^{* *} \leq \mathrm{R} *$ such that $\mathrm{x}$ en-@ $\mathrm{R} * *$. Since $\mathrm{x}$ ex-@ $\mathrm{R}^{*}, \mathrm{R}^{* *}=\mathrm{R}^{*}$ and so $\mathrm{R}^{* *} \circ \mathrm{R}$. Hence, $\mathrm{x}$ we-@ $\mathrm{R}$. (b) The left-to-right direction is direct via Exactitude. The other direction follows from Monotonicity. (c) Almost identical to (a).

Assuming Exactitude and Focus (equivalently: and Functionality-see Proposition 10), biconditionals (a), (b) and (c) are equivalent to the biconditionals that correspond to the definitions in Parsons\#1 (remember Proposition 7).

For any occupier $\mathrm{x}$, let $\mathrm{E}(\mathrm{x})$ be the collection of all the regions exactly occupied by $\mathrm{x}$. By Localisation and Exactitude, $\mathrm{E}(\mathrm{x})$ is nonempty for all occupiers $\mathrm{x}$. We have the following interesting proposition connecting exact location and P-exact location (I already referred to Proposition 12 (d) in $\S 3$ ): 


\section{[Proposition 12]}

If Exactitude holds, then:

(a) x P-en-@ $\mathrm{R}$ iff for all regions $\mathrm{R}^{*}$, if $\mathrm{x}$ ex-@ $\mathrm{R}^{*}$, then $\mathrm{R}^{*} \leq \mathrm{R}$;

(b) x pe-@ $\mathrm{R}$ iff $\mathrm{E}(\mathrm{x})$ covers $\mathrm{R}$;

(c) $\mathrm{x}$ P-ex-@ $\mathrm{R}$ iff for all regions $\mathrm{R} *, \mathrm{R}^{*} \circ \mathrm{R}$ iff $\mathrm{R}^{*}$ overlaps some $\mathrm{R} * * \in \mathrm{E}(\mathrm{x})$;

(d) If $\mathrm{E}(\mathrm{x})$ has a fusion, then $\mathrm{x}$ P-ex-@ $\mathrm{R}$ iff $\mathrm{R}=$ the fusion of $\mathrm{E}(\mathrm{x})$.

PROOF (a) Let $\mathrm{R}^{*}$ be a region such that $\mathrm{x}$ ex-@ $\mathrm{R}^{*}$ but not $\mathrm{R}^{*} \leq \mathrm{R}$. Then by Strong Supplementation there is a region $\mathrm{R}^{* *} \leq \mathrm{R} *$ disjoint from $\mathrm{R}$. By Proposition 11 (a), $\mathrm{x}$ we-@ $\mathrm{R}^{* *}$. By the definition of P-entire location, it follows that not x P-en-@ R. Conversely, suppose not x P-en-@ R. Then either (i) not x we-@ R or (ii) for some R* l R, x we-@ R*. If (i), then by Localisation and Proposition 11 (a), there is a region R* such that x ex-@ R* and not R* $\leq \mathrm{R}$. Suppose now (ii). Then by Proposition 11 (a), there is a region $\mathrm{R}^{* *}$ such that $\mathrm{x}$ ex-@ $\mathrm{R}^{* *}$ and $\mathrm{R}^{* *} \circ \mathrm{R}^{*}$. Since $\mathrm{R}^{*}$, $\mathrm{R}$, we cannot have $\mathrm{R}^{* *} \leq \mathrm{R}$. (b) Assume that $\mathrm{x}$ pe-@ $\mathrm{R}$, and let $\mathscr{R}$ be a collection of regions such that (i) x S-pe-@ $\mathrm{R}^{*}$ for all $\mathrm{R}^{*} \in \mathscr{R}$ and (ii). $\mathscr{R}$ covers R. By Proposition 11 (c), then, for all regions $\mathrm{R}^{*} \in \mathscr{R}$, there is a region $\mathrm{R}^{* *} \in \mathrm{E}(\mathrm{x})$ such that $\mathrm{R}^{*} \leq \mathrm{R}^{* *}$. Suppose $\mathrm{S}$ overlaps $\mathrm{R}$. Given that $\mathscr{R}$ covers $\mathrm{R}, \mathrm{S}$ overlaps some member $\mathrm{R} * \in \mathscr{R}$. But then $\mathrm{S}$ overlaps some member of $\mathrm{E}(\mathrm{x})$. Hence, $\mathrm{E}(\mathrm{x})$ covers $\mathrm{R}$. The converse holds since exact location entails strong pervasive location. (c) Suppose x P-ex-@ R. Then both x Pen-@R and x pe-@R. Assume R* o R. Since x pe-@ R, by (b) above R* overlaps some $\mathrm{R}^{* *} \in \mathrm{E}(\mathrm{x})$. For the other direction, assume $\mathrm{R}^{*}$ overlaps some $\mathrm{R} * * \in \mathrm{E}(\mathrm{x})$. Since $\mathrm{x}$ P-en-@ R, by (a) above R* $\circ \mathrm{R}$. Conversely, suppose that for all regions $\mathrm{R}^{*}, \mathrm{R}^{*} \circ \mathrm{R}$ iff $\mathrm{R}^{*}$ overlaps some $\mathrm{R} * * \in \mathrm{E}(\mathrm{x})$. The "only-if" bit and (b) above entail that $\mathrm{x}$ pe-@ $\mathrm{R}$. And the "if" bit and (a) above entail that x P-en-@ R. (d) Follows from (c) and the definition of fusion.

Let P-Exactness be just like Exactness but with P-exact location replacing exact location:

\section{P-Exactness}

Every object that is weakly located is P-exactly located.

Gabriel Uzquiano [22], working with weak location as a primitive and P-exact location defined as in Parsons\#2, established the surprising result that with GEM in the background, if the following principle holds, then so does P-Exactness:

\section{Atomicity}

Every region is a fusion of atoms, i.e. of regions that have no proper parts.

A stronger result can be established in the present context, also assuming GEM. The following two principles may be taken as axiomatic:

\section{[Axiom] Top-Down}

If collection of regions $\mathscr{R}$ covers region $\mathrm{R}$ and $\mathrm{x}$ we- $@ \mathrm{R}$, then for some region $\mathrm{R}^{*} \in \mathscr{R}, \mathrm{x}$ we-@ $\mathrm{R}^{*}$. 


\section{[Axiom] Remainder}

If not x pe-@ $\mathrm{R}$, then for some region $\mathrm{R}^{*}, \mathrm{R}^{*} \circ \mathrm{R}$ and not $\mathrm{x}$ we-@ $\mathrm{R} *$ (Assuming the mereological conception of location (see $\S 4$ ), weak location is overlap and pervasive location the converse of parthood; Top-Down then follows from the definition of 'covers' and Remainder from Strong Supplementation.) Let P-Exactitude be the following principle:

\section{P-Exactitude}

For all regions $\mathrm{R}$ such that $\mathrm{x} \mathrm{P}$-en-@ $\mathrm{R}$, there is a region $\mathrm{R}^{*} \leq \mathrm{R}$ such that $\mathrm{x} \mathrm{P}$ ex-@ R*.

Note that P-Exactitude entails P-Exactness: for any occupier $\mathrm{x}, \mathrm{x}$ is P-entirely located at the fusion $\mathrm{R}$ of all the regions ( $\mathrm{R}$ exists given the assumption that GEM holds), and so by $\mathrm{P}$-Exactitude $\mathrm{x}$ is P-exactly located at some region.

Using Top-Down and Remainder, one can prove the stronger result alluded to above: ${ }^{16}$

\section{[Proposition 13]}

If Atomicity holds, then so does P-Exactitude (and hence P-Exactness).

PROOF Assume Atomicity. Where $\mathrm{T}$ is any region, we let $[\mathrm{T}]$ be the collection of atoms such that T is the fusion of [T]. Suppose x P-en-@S. Let. $\mathscr{R}$ be the collection of atoms in $[\mathrm{S}]$ at which $\mathrm{x}$ is weakly located. Given that $[\mathrm{S}]$ covers $\mathrm{S}$, by Top-Down $\mathscr{R} \neq \varnothing$. Then $\mathscr{R}$ has a fusion, $\mathrm{R}$, that is a sub-region of $\mathrm{S}$. We want to show that x P-ex-@ R.

Inspecting the proof of Proposition 5 (b), one can see that Focus is needed only at the end of the proof, via appeal to Proposition 5 (a), to establish that if an occupier is not pervasively located at a region, then there is a region at which the occupier is not weakly located which overlaps the first region. But this is exactly what Remainder says. So, without assuming Focus, given Remainder we have:

(A) x P-ex-@ R iff for all regions T, xwe-@ T iff $\mathrm{T} \circ \mathrm{R}$.

We also have the following:

(B) For all regions T, xwe-@ T iff for some A $\in[\mathrm{T}]$, $\mathrm{x}$ we-@ A.

(C) For all regions $\mathrm{T}, \mathrm{T} \circ \mathrm{R}$ iff $[\mathrm{T}] \cap[\mathrm{R}] \neq \varnothing$.

The left-to-right direction of (B) follows from Top-Down, and the other direction from the definition of weak location.

Given (A)-(C), in order to establish that x P-ex-@ R, it is enough to establish the following: For all regions $\mathrm{T}$, (for some $\mathrm{A} \in[\mathrm{T}]$, $\mathrm{x}$ we-@ A) iff $[\mathrm{T}] \cap[\mathrm{R}] \neq \varnothing$.

\footnotetext{
${ }^{16}$ Uzquiano also invokes a principle he takes as axiomatic in his proof, the principle he calls 'Inheritance'. (202).
} 
Suppose there is an $A \in[T]$ such that x we-@ A. Since x P-en-@ S (see the very beginning of the proof), we must then have $\mathrm{A} \circ \mathrm{S}$, and so $\mathrm{A} \leq \mathrm{S}$, and so $\mathrm{A} \in \mathscr{R}$. Since $\mathscr{R}=[\mathrm{R}]$, we conclude that $[\mathrm{T}] \cap[\mathrm{R}] \neq \varnothing$. The other direction is immediate.

Thanks to Proposition 7, we then get as a corollary:

\section{[Proposition 14]}

If Atomicity and Focus hold, then so does Exactitude (and hence Exactness).

This proposition will be useful in $\S 8$.

\section{An Application: Endurance Vs Perdurance without Exactitude}

Gilmore [4] gave what is now taken to be a standard characterisation of the endurance / perdurance distinction in terms of location. The relevant space of regions here is the set of all the regions of spacetime. Gilmore proceeds as follows (the characterisations of endurance and perdurance below are not phrased like Gilmore's, but they are equivalent). Say that a region is achronal iff for any points $\mathrm{R}$ and $\mathrm{S}$ in the region, neither $\mathrm{R}$ nor $\mathrm{S}$ is absolutely earlier than the other (as is usual, spacetime is taken to be composed of spacetime points). An object endures iff (i) it is exactly located at, and only at, achronal regions and (ii) the fusion of these locations is not achronal. An object perdures iff (i) it has one and only one exact location and (ii) that location is not achronal.

This characterisation is unproblematic if Exactitude is true. But it surely misses something if we are open to the possibility that Exactitude is false: surely, even in this case the endurance / perdurance distinction should make sense.

Failures of Exactitude may be linked to the gunky character of the relevant space of regions. Hence, in order to reach maximal generality, we must not define achronality in terms of points. I will not suggest how this can be done. Luckily, the only principle about achronality that I will need below is that all parts of an achronal region must themselves be achronal, and this principle must surely hold whatever the definition of achronality. $^{17}$

Here is my suggestion for a characterisation of perdurance:

\section{[Definition] Perdurance}

$\mathrm{x}$ perdures iff $_{\mathrm{df}}$ (i) $\mathrm{x}$ is not multilocated and (ii) there is no achronal region at which $\mathrm{x}$ is entirely located.

\footnotetext{
${ }^{17}$ Leonard [23] proposes a definition of endurance for objects in gunky spacetime which I do not have the space to properly discuss. One important difference between his approach and mine lies in the primitive locational notions that we use. While I only use entire location, he uses both entire location (which he calls 'containment', 765) and a further notion, that of the "path" of an object in spacetime (767, footnote 32), where the path of an object is its P-exact location if Exactitude is assumed. I find this primitive notion of path mysterious: I do not see which region of gunky spacetime could possibly be the path of an occupier that has no exact location (e.g. of a point-shaped material object).
} 
If Exactitude is assumed, then perdurance in my sense and perdurance in Gilmore's sense coincide.

ProOF Assume Exactitude holds. Let $\mathrm{x}$ be an occupier. Then by Proposition 9, $\mathrm{x}$ is not multilocated iff $\mathrm{x}$ does not have distinct exact locations. By Localisation, thus, $\mathrm{x}$ is not multilocated iff $x$ has one and only one location. (1) Suppose $x$ perdures in my sense. By (i), $x$ is not multilocated, and hence, as we just saw, $x$ has a unique exact location. By (ii), that location is not achronal. Hence, x perdures in Gilmore's sense. (2) Conversely, suppose $\mathrm{x}$ perdures in Gilmore's sense. Then $\mathrm{x}$ has a unique exact location, and hence $\mathrm{x}$ is not multilocated. Let $\mathrm{R}$ be $\mathrm{x}$ 's exact location. By Gilmore's definition, $\mathrm{R}$ is not achronal. Since the regions at which $\mathrm{x}$ is entirely located are those that contain $\mathrm{R}$, these regions are not achronal either. Hence, x perdures in my sense.

And here is my suggestion for endurance:

\section{[Definition] Endurance}

$x$ endures iff $f_{d f}(i)$ if $x$ is entirely located at a region $R$, then $x$ is entirely located at an achronal sub-region of $\mathrm{R}$ and (ii) there is a non-achronal region at which $\mathrm{x}$ is pervasively located.

If Exactitude is assumed, then endurance in my sense and endurance in Gilmore's sense coincide.

PROOF Assume Exactitude holds. (1) Suppose x endures in my sense. By Localisation, Exactitude and (i), $\mathrm{x}$ is exactly located at some achronal regions. By (i), $\mathrm{x}$ is exactly located only at achronal regions. Let $\mathrm{R}$ be as stated in (ii). This means that there is a collection of regions $\mathscr{R}$ such that (a) $\mathrm{x}$ is strongly pervasively located at $\mathrm{R} *$ for all $\mathrm{R} * \in$ $\mathscr{R}$ and (b) $\mathscr{R}$ covers R. Given Exactitude and Proposition 11 (c), $\mathrm{x}$ is strongly pervasively located at a region iff $\mathrm{x}$ is exactly located at a super-region. Hence, by (a) and (b) we have that $\mathrm{R}$ is a part of the fusion of x's exact locations. Given that $\mathrm{R}$ is not achronal, the fusion is not achronal either. (2) Conversely, suppose $\mathrm{x}$ endures in Gilmore's sense. Then (i) follows from Exactitude. Let $\mathscr{R}$ be the collection of x's exact locations and let $\mathrm{R}$ be the fusion of its members. Then $\mathscr{R}$ covers $\mathrm{R}$, and by Proposition $1, \mathrm{x}$ is strongly pervasively located at each of its members. It follows that $\mathrm{x}$ is pervasively located at R. Since $x$ endures in Gilmore's sense, R is not achronal. Hence, (ii) is satisfied.

(In both proofs I rely on Localisation. An alternative would be to add to each definition a clause to the effect that the object is entirely located somewhere.)

\section{Objections and Replies}

In this last section I formulate two objections to the proposed theory of location and give my replies.

AN ARGUMENT FROM QUANTUM PHENOMENA. In $\$ 2$, I argued for the possibility that Exactness fails by invoking pointy occupiers of gunky physical space or spacetime. Some quantum phenomena are sometimes used for the same purpose (see e.g. [24]: $\S 4.3$, who cites [25]: 467). A consequence of the Heisenberg uncertainty principle is 
that a particle cannot have (at a given time) both a determinate position and a determinate momentum. Consider an electron which, as per the principle, does not have a determinate position. It is nevertheless clear that there are regions that are not completely free of the electron, e.g. the whole of space. Hence there are objects that are weakly located without being exactly located. Therefore, failures of Exactness actually occur. Therefore, failures of Exactness are possible.

I did not mention this argument when I argued for the possibility that Exactness fails because of the result expressed by Proposition 14 from $\S 6$. The quantum phenomena in question are normally taken to occur in physical space understood as made up of points, and therefore Atomicity should be taken for granted in the argument. I take it that multilocation is not relevant for the phenomena under consideration, and therefore that Focus can unproblematically be assumed to hold. That said, by Proposition 14, Exactitude, and hence Exactness, should hold in the situations under consideration.

Some might turn the previous considerations into a simple objection against my theory: since Exactness obviously fails in these situations, the objection goes, there must be something wrong with my theory. My reply is to deny that Exactness fails in the situations in question. An easy way out is to advocate a Bohmian interpretation of quantum mechanics and hold that the uncertainty principle merely states the impossibility of having a precise measure of both parameters at a given time. But there is a more straightforward, and in my view more accurate, reply that does not assume this non-standard interpretation.

In the situation introduced above, the electron - call it ' $E$ ' - does not have a determinate position. But 'determinate position' does not mean 'exact location', it means 'determinate exact location'. And to say that E does not have a determinate exact location is to make the following probabilistic statement:

a) For all regions $\mathrm{R}$, prob.(E ex-@ R) $<1$.

Now once the distinction between what has probability 1 and what has probability less than 1 of being the case is on the table, the question of whether the electron case undermines Exactness becomes the question of whether it undermines the following conditional:

b) If prob.(For some R, E we-@ R) = 1, then prob.(For some R, E ex-@ R) = 1 .

The antecedent is by hypothesis true - because, say, the probability that the electron is entirely located at this room is 1 . The electron case would thus falsify b) if it falsified its consequent:

c) prob.(For some R, E ex-@ R) = 1 .

But, I contend, the electron case verifies c). In the relevant probability space, the "possible outcomes" are all situations in which the proposition < For some R, E ex-@ $\mathrm{R}>$ is true, which is why c) holds. The reason why a) nevertheless also holds is that the regions that witness the truth of this proposition vary from situation to situation, in such a way that for any region $\mathrm{R}$, there are situations at which the proposition $<$ E ex-@ $\mathrm{R}>$ is false. Formally speaking, the case is 
similar to what happens in supervaluation semantics: it may be super-true that some man in a sorites series marks the limit between the bald and the non-bald, even if there is no particular man such that it is super-true that he marks the limit between the bald and the non-bald. ${ }^{18}$

KLEINSCHMidT'S SITUATION. Kleinschmidt [6] puts forward the following situation: an almond is entirely located at a region that is bigger than the almond and that has no proper parts. She uses this situation to argue that no theory of location based on a single primitive locational relation is viable. We do not need to bother about the details of her argument. The important point is that it involves the claim that in the situation in question, the almond is not exactly located at the region. Now if the claim were correct, then my definition of exact location would have to be rejected: since by hypothesis the almond is entirely in the region and the region has no proper parts, my definition predicts that the almond is exactly located at the region.

The almond is not exactly located at the region, Kleinschmidt holds, because the former is smaller than the latter. This argument is reminiscent of Gilmore's [4] gloss on exact location (see $\S 1$ ). Remember the caveat following my presentation of the gloss: it is good as it stands for certain kinds of spaces of regions, not for others. I think Kleinschmidt's situation is precisely one where the gloss in inadequate. Suppose for comparison that we focus on a space of locations consisting of the (physical realization of) Switzerland's cantons and their fusions. Suppose Claudio is entirely in Ticino, while Maria is crossing the border between Ticino and Uri, so that she is neither entirely in Ticino nor entirely in Uri. It is perfectly correct to say that relative to the system of locations under consideration, Claudio is exactly located at (in better English: in) Ticino, and at no other region, while Maria is exactly located at the fusion of Ticino and Uri, and at no other region. Claudio is much smaller than Ticino, and Maria than Ticino + Uri, but this is not a problem. Of course, there is a spatial region $\mathrm{R}$ within Ticino that has the very same shape and size as Claudio, and relative to a system of locations consisting of all the regions of $3 \mathrm{D}$ space it is $\mathrm{R}$ that would count as Claudio's exact location, not Ticino. But this remark does not undermine my locational claims about Claudio and Maria, since the system of locations alluded to is not the original one. My reply to Kleinschmidt's argument is thus simply that size does not matter: given the system of locations she considers, the almond is exactly located at the region. ${ }^{19}$

\footnotetext{
${ }^{18}$ Say that an object $\mathrm{x}$ is $E X A C T L Y$ located at a region $\mathrm{R}$ iff ${ }_{\mathrm{df}}$ prob.(x en-@ $\left.\mathrm{R}\right)=1$ and there is no region $\mathrm{R}^{*}<\mathrm{R}$ such that prob.(x en-@ $\left.\mathrm{R}^{*}\right)=1$. The proposition that E is EXACTLY located at the whole of space is true simpliciter, it has probability 1 of being true. Yet one should not be tempted to infer that the proposition that $\mathrm{E}$ is exactly located at the whole of space is true. EXACT location and exact location are different things, and the inference is not valid.

${ }^{19}$ See [9]: 167 for a similar reply. My argument is of course compatible with the view that in addition to the notion of exact location I am interested in in this paper, there are other notions that deserve the same name and that are intrinsically sensitive to size in the way suggested by Kleinschmidt. The argument is also compatible with the view that still other notions of exact location are sensitive to parameters other than size. Such a notion, I contend, is at work in Daniel Nolan's [26] discussion of Stoic blends. If a Stoic blend of water and wine is exactly located at a given region R (say, within a glass), the following is supposed to be true: the water and the wine are weakly located at every subregion of $\mathrm{R}$, yet neither has an exact location, because "[t]he wine is so scattered and discontinuous that it will not exactly fit any of the continuous [sub-]regions of [R]" ([2]: 208). On my account, the water and the wine are both exactly located at R: each is entirely located at R, and none is entirely located at a proper sub-region of $\mathrm{R}$.
} 
Acknowledgements Versions of this paper have been presented in October 2020 at an eidos meeting (University of Geneva), in March 2021 at a session of the Lingnan/HKU/NUS Seminar Series and in April 2021 at a session of the Hebrew University of Jerusalem's Philosophy Department Seminar. I am grateful to the participants of these events for very helpful feedback, especially to Claudio Calosi, Damiano Costa, Antony Eagle, Olivier Massin, Giovanni Merlo, David Schroeren and Lisa Vogt, as well as to two referees for this journal. This work was supported by the Swiss National Science Foundation's Consolidator project BSCGI0_157792.

Funding Open Access funding provided by Université de Genève.

Open Access This article is licensed under a Creative Commons Attribution 4.0 International License, which permits use, sharing, adaptation, distribution and reproduction in any medium or format, as long as you give appropriate credit to the original author(s) and the source, provide a link to the Creative Commons licence, and indicate if changes were made. The images or other third party material in this article are included in the article's Creative Commons licence, unless indicated otherwise in a credit line to the material. If material is not included in the article's Creative Commons licence and your intended use is not permitted by statutory regulation or exceeds the permitted use, you will need to obtain permission directly from the copyright holder. To view a copy of this licence, visit http://creativecommons.org/licenses/by/4.0/.

\section{References}

1. Simons, P. (2004). Location. Dialectica, 58, 341-347.

2. Parsons, J. (2007). Theories of location. In D. Zimmerman (Ed.), Oxford Studies in Metaphysics (Vol. 3, pp. 201-232). Oxford University Press.

3. Gilmore, C. (2008). Persistence and location in relativistic Spacetime. Philosophy Compass, 3, 1224-1254.

4. Gilmore, C. (2006). Where in the relativistic world are we? Philosophical Perspectives, 20, 199-236.

5. Calosi, C., \& Costa, D. (2015). Multilocation, fusions, and confusions. Philosophia, 43, $25-33$.

6. Kleinschmidt, S. (2016). Placement permissivism. Journal of Philosophy, 113, 117-236.

7. Hudson, H. (2005). The metaphysics of hyperspace. Oxford University Press.

8. Parsons, J. (2008). Hudson on location. Philosophy and Phenomenological Research, 76, 427-435.

9. Eagle, A. (2019). Weak location. Dialectica, 73, 149-181.

10. Eagle, A. (2010). Location and Perdurance, in D. Zimmerman (ed.), Oxford Studies in Metaphysics, Volume 5, Oxford University Press, 53-94.

11. Casati, R., \& Varzi, A. (1999). Parts and places: The structures of spatial representation. MIT Press.

12. Leonard, M. (2014). Locating gunky water and wine. Ratio, 27, 306-315.

13. Loss, R. (2019). How to make a gunky spritz. Thought: A Journal of Philosophy, 8, 250-259.

14. Loss, R. Forthcoming. Somewhere together: Location, parsimony and multilocation, Erkenntnis.

15. Schaffer, J. (2010). Monism: The priority of the whole. Philosophical Review, 119, 31-76.

16. Costa, D. \& Calosi, C. Forthcoming. The multi-location trilemma, Erkenntnis.

17. Effingham, N., \& Robson, J. (2007). A mereological challenge to endurantism. Australasian Journal of Philosophy, 85, 633-640.

18. Gilmore, C. (2007). Time travel, coinciding objects, and persistence, Oxford Studies in Metaphysics (Vol. 3, pp. 177-198). Oxford University Press.

19. Gilmore, Cody, "Location and Mereology", The Stanford Encyclopedia of Philosophy (Fall 2018 Edition), Edward N. Zalta (ed.), https://plato.stanford.edu/archives/fall2018/entries/location-mereology/.

20. Kleinschmidt, S. (2011). Multilocation and mereology. Philosophical Perspectives, 25, 253-276.

21. Eagle, A. (2016). Multiple location defended. Philosophical Studies, 1738, 2215-2231.

22. Uzquiano, G. (2011). Mereological harmony, in K. Bennett \& D. Zimmerman (eds.), Oxford Studies in Metaphysics, Volume 6, Oxford University Press, 199-224.

23. Leonard, M. (2018). Enduring through gunk. Erkenntnis, 83, 753-771.

24. Calosi, C. Forthcoming. Determinables, location, and indeterminacy, Synthese.

25. Bokulich, A. (2014). Metaphysical indeterminacy, Properties, and Quantum Theory. Res Philosophica, 91, 449-475.

26. Nolan, D. (2006). Stoic gunk. Phronesis, 51, 162-183.

Publisher's Note Springer Nature remains neutral with regard to jurisdictional claims in published maps and institutional affiliations. 